\title{
¿FUE VULGAR Y PLEBEYO EL ORIGEN DE USTED? LA DIACRONÍA DEL PRONOMBRE DE RESPETO DESDE LA INTERFAZ ORAL/ESCRITO*
}

\author{
MARÍA TERESA GARCÍA-GODOY \\ Universidad de Granada
}

\section{RESUMEN}

Los estudios del cambio vuestra merced > usted, de forma unánime, señalan las dificultades reconstructivas de la fase de univerbación en la lengua no literaria, en la que apenas existen huellas de las formas pronominales. Así, con independencia del paradigma teórico aplicado, la historia de usted y sus alomorfos, empíricamente, se viene sustentando en un único género discursivo: la comedia clásica. Al parecer, la lengua hablada por los tipos teatrales del siglo XVII ofrece las únicas evidencias evolutivas del pronombre de respeto, toda vez que la lengua escrita de la época exhibe, exclusivamente, el sintagma vuestra merced. Por este motivo, solo conocemos la biografía literaria de usted, pronombre que se vincula con los personajes más plebeyos y vulgares del teatro. En este trabajo se explora una nueva base empírica de documentos no literarios y se muestra la diferente estratificación de usted y sus alomorfos dentro y fuera de la escena clásica. Asimismo, el presente trabajo demuestra que son factores diafásicos y no diastráticos los que determinan la biografía no literaria del pronombre de respeto.

PALABRAS CLAVE: Historia del español, morfología histórica, evolución del pronombre de respeto, variación y estandarización lingüisticas, lingüistica de corpus.

\section{AbSTRACT}

Regarding the evolution of polite forms from vuestra merced to usted, all studies to date unanimously point out the difficulties inherent in reconstructing its univerbation phase in non-literary language, in which pronominal forms have left scant traces. Regardless of the theoretical paradigm, the history of usted and its allomorphs has empirically been based on a single discourse genre: classical comedy. Apparently, the language used by theatrical characters of the $17^{\text {th }}$ century

* Este trabajo se enmarca en el proyecto I+ D de referencia FFI2013-46207P, financiado por el Ministerio de Economía y Competitividad (MINECO). 
is the only repository of evidence for the evolution of the pronoun of respect, given that other written sources of the era only display uses of the phrase vuestra merced. For this reason, only the literary history of usted is known to us, and then only as a pronoun used by the lowest and most vulgar dramatic characters. The present study explores a new empirical base of non-literary documents to show the varying stratification of usted and its allomorphs inside and out of the classical scene. In addition, this work provides proof that it is diaphasic and not diastratic factors that determine the non-literary history of the formal pronoun.

KEYWORDS: History of Spanish, Historical morphology, Evolution of formal pronouns, Linguistic variation and standardization, Corpus linguistics.

\section{INTRODUCCIÓN}

En la historia del español, el pronombre de respeto exhibe un acusado polimorfismo en el periodo aurisecular. Hacia 1690 se fecha la generalización de la actual forma usted, a costa de las numerosas variantes morfofonéticas que, durante todo el siglo XVII, habían coexistido en el uso literario (Pla Cárceles, 1923a; De Jonge y Nieuwenhuijsen, 2009). La variación morfológica del pronombre de respeto se cifra en casi una veintena de formas (vuesarced, vuaced, vuced; vuesasted, vusted, usted, etc.), cuyo empleo viene caracterizándose con la marca vulgar, en los estudios previos (Lapesa, 2000 [1970]). Este carácter subestándar que, en el español clásico, se atribuye al pronombre usted y a sus alomorfos se fundamenta en el hecho de que las primeras documentaciones de dichas formas se vinculan con tipos literarios de baja extracción social. Toda vez que las evidencias empíricas más tempranas del pronombre de respeto corresponden a usos teatrales de las clases más bajas, la marca vulgar se hace extensiva a todo el proceso de univerbación vuestra merced > usted durante el siglo XVII, límite temporal en la mayoría de las investigaciones sobre dicho cambio morfosintáctico. En efecto, los estudios previos han magnificado la biografía literaria del pronombre de respeto, de modo que, aun hoy, desconocemos si la lengua no literaria confirma o desmiente ese origen plebeyo de usted, en la comedia clásica. Por tal motivo, se explorará aquí un corpus de documentación histórica (corpus CORDEREGRA) de impronta oralizante y, empíricamente, se ofrecerán evidencias del uso no literario de usted (siglos XVII y XVIII).

Este estudio postula que el pronombre de respeto puede manifestar diferente estratificación de uso en los géneros literarios y en los no literarios. Los gramáticos ilustrados sostienen que usted era forma apta para hablar, pero no para escribir (Sáez Rivera, 2006). Esta fuerte restricción discursiva del nuevo pronombre en dicho lapso explicaría la dificultad de reconstruir el cambio vuestra merced > usted fuera de la lengua teatral. Solo en el 
género literario más dialógico afloran los innovadores usos de usted y sus alomorfos, en contextos coloquiales. En efecto, apenas existen huellas del pronombre en la lengua no literaria de los siglos XVII y XVIII. En todas las etapas históricas del español, el canon retórico de lengua escrita había entronizado el uso conservador del sintagma vuestra merced en la mayoría de géneros textuales, inhibiendo así las innovadoras pronunciaciones univerbales, muy vinculadas con la lengua hablada en la que se forjó el pronombre de respeto (García-Godoy, 2012). Por todo ello, la búsqueda de dicho "dialogismo" en la lengua no literaria podría arrojar una nueva luz sobre la enigmática fase oral del cambio vuestra merced > usted. Aquellos documentos históricos más vinculados con la inmediatez comunicativa (Oesterreicher, 2005), infrainvestigados en los estudios previos, podrían ofrecer una nueva visión diacrónica del pronombre usted y sus alomorfos.

Además de la presente introducción, este trabajo se compone de siete apartados. En primer lugar, se delimita el marco epistemológico y se formulan los objetivos. A continuación (apartado 2), se ofrece un sucinto balance bibliográfico sobre el estatus variacional de usted y sus alomorfos en la investigación diacrónica. En el apartado 3 se describe el corpus y, seguidamente (apartado 4), se muestran todas las evidencias empíricas del pronombre, aportadas por dicho corpus. Ya en el apartado 5, previo a las conclusiones, se analiza el tipo de variación lingüística que opera en el trío de formas pronominales, atestiguado en el corpus (vusted, usted, osted). Finalmente, el séptimo y último apartado incluye la bibliografía.

\section{Marco teórico, objetivos y PLANTEAmiento MEtodológico}

Desde el punto de vista teórico, el género discursivo se esgrime como un factor relevante en el estudio del cambio lingüístico (Kabatek, 2005; Company, 2008) y adquiere especial importancia en la diacronía del tratamiento de merced (Koch, 2008). En la tradición gramatical, desde el Medievo hasta el siglo xix, la rúbrica "tratamiento de merced" se consolida para mencionar cualquier estadio evolutivo del pronombre de respeto, de modo que con dicha denominación se alude tanto al sintagma primigenio (vuestra merced), como a su derivado pronominal (usted) (GarcíaGodoy, 2012: 111).

En este marco epistemológico, resulta esclarecedor el análisis de Ly (2001) sobre el determinismo retórico de los tratamientos alocutivos en el teatro clásico español. Así, el tuteo latinizante, plasmado en las obras teatrales del Siglo de Oro, obedece a la herencia retórica del género dramático y, en modo alguno, representa la generalización del pronombre tú 
en la lengua no literaria de la época (Ly, 2001: 13 y 15) ${ }^{1}$. Ly demuestra, fehacientemente, las divergencias entre el código sociodramático y el código sociolingüístico en el paradigma de los tratamientos honoríficos auriseculares. En consecuencia, la historia teatral del tratamiento de merced presenta un importante sesgo teórico, al obviar los fenómenos de variación y cambio condicionados por la tradición retórica, particularmente intensa en el teatro en verso. Por ello, no resulta aventurado pensar que las fuentes teatrales puedan cobijar una imagen sesgada del cambio vuestra merced > usted, en lo atinente al proceso de univerbación. Los estudios previos no permiten responder a la pregunta que constituye el hilo conductor del presente estudio: ¿el árbol genealógico de usted y su carácter vulgar se circunscribe solo al género dramático?

Por otra parte, cabe poner de relieve que teórica y metodológicamente la cabal reconstrucción del cambio vuestra merced > usted necesita aunar dos disciplinas: la filología y la lingüística. Como es sabido, los problemas de fiabilidad filológica minan la base empírica literaria, muy privilegiada en la investigación diacrónica del pronombre usted. El principal escollo lo encontramos en las ediciones modernas de la abreviatura vmrd. (o sus variantes $v m d$., vm., etc.), con la que, mayoritariamente, se escribió el denominado tratamiento de merced en todos sus estadios evolutivos (GarcíaGodoy, 2012: 118-125). Como es sabido, en la historia del español se oficializó la norma escrituraria abreviada para los sintagmas honoríficos. En el caso que nos ocupa, casi constituye una rareza documentar en escritura plena el sintagma vuestra merced, el pronombre usted y los desgastes fonéticos que lo precedieron. En las fuentes teatrales, editadas modernamente, la convención métrica de la rima suele ser el principal parámetro considerado por el editor para desatar "creativamente" la abreviatura vmrd. El hecho de que, lingüísticamente, la fase de univerbación del pronombre se haya reconstruido sobre variantes del editor literario, distintas de las del autor ${ }^{2}$, siembra de dudas la mayoría de los estudios previos, inclusive aquellos basados en el corpus académico CORDE, en el que se incluyen ediciones de escasa fiabilidad filológica. Las distorsiones cronológicas y los vacíos informativos sobre variantes dialectales ponen bajo sospecha las in-

1 Para el siglo xv Eberenz (2000: 98-100) señala, igualmente, que algunos tipos textuales latinizantes exhiben también el mismo tuteo generalizado, ajeno a los usos sociales de la época.

2 Pla Cárceles ya advierte de estos problemas de fiabilidad filológica, incluso en textos editados por académicos. Así, en la edición que, en 1911, hace Cotarelo de una obra de Hurtado de Mendoza (Getafe), incluida en su Colección de entremeses, el Secretario de la RAE adopta vuçé "guiado por las Obras del autor, publicadas en 1728", cuando la edición de 1621 de Getafe, conservada en el Museo Británico, Pla Cárceles reconoce no haber visto la tardía variante vuçé sino otra más temprana: buesarçed (Pla Cárceles, 1923a: 262, nota 3). 
vestigaciones basadas en un uso irreflexivo del corpus CORDE, como bien han demostrado Lleal Galcerán (2013) y Rodríguez Molina (2015), entre otros.

Atendiendo a estos problemas, el análisis aquí proyectado obvia cualquier interpretación de la abreviatura vmd. y se centra, exclusivamente, en las formas pronominales inequívocas, atestiguadas en una nueva base empírica no literaria (corpus CORDEREGRA). Los documentos de este corpus, transcritos con rigor paleográfico y fiabilidad filológica, ofrecen numerosas evidencias textuales del pronombre de respeto en escritura plena. Como se muestra en el apartado 4, los nuevos hallazgos documentales de usted y sus alomorformos se han localizado, sobre todo, en el tipo textual autos, en aquellos pasajes en que los testigos, en la vista oral, rememoran literalmente lo expresado en el lugar del delito (parte declaratoria de pleitos criminales).

En este trabajo se pretende demostrar que, durante su primer siglo de vida, el pronombre de respeto manifiesta una fuerte dependencia del discurso directo. Por ello, aquellas tipologías textuales que, por tradición retórica, inhiben el "dialogismo", durante siglos, no fueron permeables a la forma usted (ni a sus variantes morfofonéticas).

Por discurso directo entendemos aquel que reproduce de manera literal las palabras propias o ajenas, sin la presencia de un nexo que conecte una oración sustantiva de objeto directo con la oración principal (RAE-ASALE, 2009: 3273). Únicamente los verbos de determinadas clases semánticas (dicción, comunicación) pueden introducir el discurso directo, que manifiesta, por lo general, una sintaxis libre (Cano, 2000: 103; Barraza, 2014: 3054), propia de la lengua oral. El siguiente ejemplo del CORDEREGRA (1) ilustra un uso de usted en discurso directo:

(1) 1665 [Unos salteadores de camino roban y dan muerte a Antonio Jorge]. Bio que el dicho onbre estaba baqueteando todabía la escopeta y por dos beçes dijo: "al que se meneare, matarlo". Y así que acabó y metió la baqueta, por miedo de que no lo matase si lo biera, se bolbió a tapar la cara, y así que lo iço, dijo el dicho onbre cano: “¿dónde van?”, y sus compañeros del testigo rrespondieron: "a Ronda", y él dijo: "benga el dinero"; y Antón Moreno, qu'estaba acostado junto a el testigo, dijo: "be usted aquí unos quartos que traygo" (Calderón, 2015: 183).

El fin principal de este trabajo es explorar, por primera vez, el polimorfismo del cambio vuestra merced > usted en un corpus de documentos históricos, para determinar si las variantes pronominales exhiben la misma estratificación de uso dentro y fuera de la escena clásica. Como objetivos secundarios, se formulan estos dos: $1^{\circ}$ identificar las variantes formales del pronombre de respeto compartidas por la lengua literaria y no literaria; $2^{\circ}$ reformular la cronología del proceso de univerbación, atendiendo a las nuevas evidencias del polimorfismo dieciochesco del pronombre. 


\section{VARIACIÓN DIACRÓNICA Y DIASTRÁTICA EN EL NACIMIENTO DEL PRONOMBRE DE RESPETO. ESTADO DE LA CUESTIÓN}

En las gramáticas históricas de la lengua española constituye un foco de interés trazar el árbol genealógico del pronombre usted, a partir del sintagma primigenio vuestra merced. Datar la fusión del sintagma en pronombre (proceso de univerbación) y determinar, cronológicamente, la longevidad de las múltiples variantes pronominales son aspectos destacados en los estudios previos (Pla Cárceles, 1923a: 280; Alvar y Pottier, 1983: 130-131; Lapesa, 1970: 146-149; De Jonge, 2005; De Jonge y Nieuwenhuijsen, 2009: 1651). En ellos descuella, asimismo, la preocupación por precisar el valor sociolingüístico de ese polimorfismo pronominal. Con todo, el estado de conocimientos apenas se ha modificado en el último siglo y persisten los vacíos informativos sobre la profundidad histórica de las diferentes variantes polimórficas y su estratificación de uso. En buena medida, esta situación obedece al hecho de que, con independencia del paradigma teórico con el que se haya abordado el cambio vuestra merced > usted, siempre se han explorado las mismas obras literarias. La débil fundamentación empírica es un denominador común en los estudios previos. Sobre idénticas fuentes teatrales, no siempre editadas con fiabilidad filológica, se han cimentado todas las hipótesis sobre la historia del pronombre de respeto. Por ello, la biografía oficial de usted es prácticamente la misma desde los primeros estudios de Pla Cárceles (1923a, 1923b) hasta los más recientes, basados en el corpus CORDE (De Jonge y Nieuwenhuijsen, 2009): nace en los diálogos teatrales hacia $1620^{3}-1629^{4}$ (Pla Cárceles, 1620b; cfr. De Jonge y Nieuwenhuijsen, 2009: 1646), conviviendo con múltiples variantes morfofonéticas (véase figura 1). La obsolescencia de dichas variantes se fecha hacia los últimos años de esa misma centuria, momento en el que la octogenaria forma usted habría alcanzado ya una significativa estandarización. Lapesa defiende que usted incrementa su difusión en el tránsito de los siglos XVII y XVIII (Lapesa,

${ }^{3}$ En las gramáticas históricas del español, el año de 1620 se viene considerando la fecha de nacimiento del pronombre usted, desde el trabajo pionero de Pla Cárceles (1923b). Dicha datación se funda en un uso teatral, atestiguado en la obra El examinador miser Palomo, de Hurtado de Mendoza. Según reconoce Pla Cárceles, en la edición valenciana de dicha obra se documenta la impresión más temprana conocida de la forma usted.

${ }^{4}$ De Jonge y Nieuwenhuijsen (2009: 1646), basándose en el corpus CORDE, retrasan casi una década la datación de usted en el teatro aurisecular y aducen un ejemplo de La dama duende de 1629, sin que se pueda determinar si ese uso corresponde al autor (Calderón de la Barca) o al editor moderno Vern G. Williamsen (La dama duende, Universidad de Arizona, 1995). El corpus académico, actualmente, corrobora esa vinculación de la lengua teatral con las primeras documentaciones de usted (c. 1620), aunque la poca fiabilidad filológica de las ediciones del CORDE impide establecer cronologías seguras. 
2000 [1970]: 320), mientras que De Jonge y Nieuwenhuijsen (2009: 1646) sostienen que dicha variante "se convierte en la forma de uso general a fines del siglo XVII".

En este apartado, atendiendo a la bibliografía previa, se intentará responder a estas dos preguntas en la historia del español: ¿cuál es la trayectoria diacrónica de los alomorfos del pronombre de respeto? ¿Qué valoración sociolingüística se otorga a dichas variantes pronominales?

\subsection{El polimorfismo del pronombre de respeto: variación diacrónica}

Casi de forma unánime, los investigadores establecen que es en el siglo XVII cuando se desarrolla la biografía de todas las variantes morfofonéticas del pronombre de respeto, en la escena clásica. Pla Cárceles (1923a) y De Jonge (2005) señalan la dificultad de datar los diferentes estadios evolutivos en el proceso de univerbación, debido al hecho de que determinadas formas carecen de primera documentación fiable. Por ello, ya en los estudios pioneros (Navarro Tomás, 1923), se cuestiona la existencia de algunas variantes, su datación e incluso el orden que se les otorga en la genealogía literaria del pronombre de respeto. De todas las evoluciones intermedias, la variante híbrida vuesasted (Navarro Tomás, 1923: 310) ${ }^{5}$ y las formas en -n-(vuesanced, vuesanted) son las que suscitan mayor controversia en la cadena de cambios fonéticos (De Jonge y Nieuwenhuijsen, 2009: 1649).

Así las cosas, en sentido lato, desde el primer trabajo de Pla Cárceles (1923a) se sostiene que, aproximadamente entre 1575 y 1620, se desarrolla todo el proceso de univerbación de vuestra merced, del que resultan formas con distinto grado de erosión fonética. Los alomorfos trisílabos (vuesarçed, vuesançed, vuesasted, etc.) son los más tempranos y, en las distintas líneas sucesorias, preceden a las formas bisílabas ( uçed, vusted, usted). La escena clásica, en ese lapso, permitiría atestiguar el nacimiento de hasta diecisiete variantes morfofonéticas del pronombre de respeto (véase tabla 1). Además, también el género teatral ofrece la fecha de defunción de los alomorfos pronominales hacia 1690, excepción hecha de usted, que, desde

\footnotetext{
${ }^{5}$ En el esquema diacrónico de Pla Cárceles (1923a) figura el eslabón evolutivo vuesançed > vuesasted. Navarro Tomás (1923: 310) señala dificultades fonéticas e irregularidades cronológicas en esa fase del cambio: "resulta difícil de admitir que el grupo st de vuesasted proceda [...] del desdoblamiento y metátesis de los dos elementos $t s$ virtualmente contenidos en la $c$ de vuesançed (vuesa merced)". Asimismo, Navarro Tomás (1923: 311) discrepa de la antigüedad que en el árbol genealógico del pronombre se le otorga al alomorfo vuesasted, toda vez que Pla Cárceles lo había considerado una forma mixta de vuesarced y usted, cuando podría tratarse de un compuesto de vuesa + usted (cfr. De Jonge y Nieuwenhuijsen, 2009: 1649).
} 
entonces, irá alcanzando el estatus de forma estándar. Naturalmente, esta hipótesis cronológica, mayoritariamente aceptada, a priori presupone que el cambio vuestra merced > usted se completa definitivamente en el siglo XVII. Igualmente, en tales estudios, a priori se acepta que las documentaciones teatrales de usted y sus alomorfos representan el uso real de la época: si, por ejemplo, formas como uçed y vuesasted nacen y mueren en el teatro aurisecular, se da por hecho que también esos alomorfos pronominales debieron existir en la lengua hablada hasta el siglo XVII. Pero ninguno de esos dos supuestos apriorísticos se ha validado empíricamente con datos no literarios, de modo que la historia de usted encierra aún hoy bastantes incógnitas: ¿Por qué se exluye la etapa postclásica en la biografía de los alomorfos pronominales? ¿Cómo explicar que esos alomorfos, con certificado de defunción teatral hacia 1690, resuciten en la escena costumbrista de los siglos XVIII y XIX? ¿Por qué solo existen evidencias de uso teatral para la mayoría de las variantes morfofonéticas del pronombre de respeto? El estado actual de conocimientos no ofrece ninguna respuesta a estos interrogantes.

No en vano, estudios recientes comienzan a cuestionar que ese estadio de variación diacrónica de la lengua teatral sea extrapolable a la lengua general. Los argumentos más sólidos para rebatir la hipótesis clásica sobre la biografía de las variantes morfofonéticas de usted se fundan en los nuevos datos localizados en las fuentes historiográficas y en la documentación histórica.

En la figura 1, se ofrece la relación alfabética de variantes pronominales mencionadas por los investigadores del cambio vuestra merced > usted, en los trabajos publicados desde 1923 hasta 2015. Igualmente, se reflejan en dicha figura los indicadores cronológicos señalados en la bibliografía previa (la fecha de la primera documentación se indica entre paréntesis). Fácilmente se advierten las discordancias históricas del pronombre en las distintas fuentes exploradas en los estudios previos. Obsérvese en la figura 1 cómo el número de alomorfos del pronombre de respeto y la biografía de cada uno de ellos es diferente en el teatro (Pla Cárceles, 1923a; De Jonge, 2005; De Jonge y Nieuwenhuijsen, 2009), en la historiografía lingüística (Sáez Rivera, 2006; Gutiérrez Maté, 2012) y en la documentación histórica (Calderón, 2015; García-Godoy, 2015). Resulta llamativo comprobar que en estos dos últimos tipos de fuentes se atestigua una misma visión diacrónica del polimorfismo pronominal, muy distinta de la documentada en la lengua del teatro. Así, frente a la profusión de variantes morfofonéticas de la lengua teatral (diecisiete formas), los documentos históricos y la historiografía lingüística ofrecen un escueto inventario de variantes pronominales: vusted y usted. Estas son, precisamente, las únicas dos formas compartidas por los tres tipos de fuentes, aunque existen significativas diferencias cronológicas entre la lengua literaria y la no literaria, como veremos enseguida. 
Figura 1. El desgaste fonético de vuestra merced en los estudios previos: presencia $(\checkmark)$ / ausencia $(x)$ de alomorfos en diversas fuentes

(año de primera documentación)

\begin{tabular}{|l|c|c|c|}
\hline VARIANTE & $\begin{array}{c}\text { FUENTES TEATRALES } \\
\text { (año } 1^{\underline{a}} \text { doc.) }\end{array}$ & $\begin{array}{c}\text { DOC. HISTÓRICOS } \\
\text { (año } 1^{\underline{a}} \text { doc.) }\end{array}$ & $\begin{array}{c}\text { GRAMÁTICAS ELE } \\
\text { (año } 1^{\underline{a}} \text { doc.) }\end{array}$ \\
\hline uçed & $\checkmark$ & $\times$ & $\times$ \\
usted & $\checkmark(1620)$ & $\checkmark(1661)$ & $\times$ \\
voaçed & $\checkmark$ & $\times$ & $\times$ \\
voarçed & $\checkmark$ & $\times$ & $\times$ \\
vosasted & $\checkmark$ & $\times$ & $\times$ \\
vuaçed & $\checkmark$ & $\times$ & $\times$ \\
vuarçed & $\checkmark$ & $\times$ & $\times$ \\
vuçed & $\checkmark$ & $\times$ & $\times$ \\
vuasted & $\checkmark$ & $\times$ & $\times$ \\
vueşed & $\checkmark$ & $\times$ & $\times$ \\
vuerçed & $\checkmark$ & $\times$ & $\times$ \\
vuesarçed & $\checkmark$ & $\times$ & $\times$ \\
vuesançed & $\checkmark$ & $\times$ & $\times$ \\
vuesansted & $\checkmark$ & $\times$ & $\times$ \\
vuesasted & $\checkmark$ & $\times$ & $\times$ \\
vuested & $\checkmark$ & $\times 1614)$ & $\times$ \\
vusted & $\checkmark$ & $\times$ & $\times$ \\
\hline
\end{tabular}

Con independencia del tipo documental explorado, los investigadores conceden especial relevancia al último eslabón evolutivo en la diacronía del pronombre de respeto, vuste $(d)>u s t e(d)$, toda vez que permite establecer hipótesis cronológicas sobre cuándo finaliza el proceso de univerbación y, por ende, se generaliza el amalgama bisílabo usted, como variante estándar. En este punto cabe subrayar que la profundidad histórica de las variantes vusted/usted difiere en los estudios basados en el género teatral y en las recientes investigaciones que comienzan a explorar otros géneros textuales.

Como ya se ha se ha mencionado, vuste(d) nace y muere en el teatro en el siglo XVII. Según De Jonge y Nieuwenhuijsen (2009: 1646), la historia de esta variante se desarrolla en la escena clásica entre 1617 y 1668, aunque las últimas investigaciones apuntan una mayor longevidad en la lengua no 
literaria. Así, en 1714, vuste(d) se atestigua en un pleito de la Real Chancillería de Granada (García-Godoy, 2015: 667) y en 1772 en un documento colonial del virreinato de la Nueva Granada (De Stéfano y Tejera, 2006: 256). Por lo que respecta al género historiográfico, en 1701, el tratado gramatical de Maunory señala la convivencia de vusted/usted ${ }^{6}$ (Sáez Rivera, 2006: 2906-2907). Además, vusted es el único alomorfo del pronombre de respeto que se registra en el diccionario de Autoridades (1739, tomo VI) y que seguirá contando con vitola académica hasta la época contemporánea (véase figura 6). Asimismo, en el siglo xx, se señala la supervivencia de vusted en algunas regiones hispanoamericanas (León, 1998: 568).

Por otra parte, también existen acusadas disparidades cronológicas en la historia de la forma usted, según la tipología documental explorada en los estudios previos. El uso teatral de 1620, aducido por Pla Cárceles (1923b), se considera la fecha oficial del nacimiento de usted. Pero esta cronología no se confirma ni en la historiografía lingüística, ni en los documentos históricos, según estudios recientes. En la historia de la gramática, la primera documentación conocida de usted data de 1697, en la obra de Francisco Sobrino (Salvador Plans, 1996: 202; Sáez Rivera, 2006: 2904). En la documentación histórica, los usos primigenios de usted se atestiguan hacia la segunda mitad del siglo XVII. García-Godoy (2015: 679) aduce usos tempranos de usted, fechados entre $1661^{7}$ y 1673 , procedentes de ediciones paleográficas rigurosas de documentos coloniales. En los pleitos de la América virreinal, las primeras documentaciones datan de 1672 en Santo Domingo (Gutiérrez Maté, 2012: 1898) y de 1673 en México (Melis y Rivero Franyutti, 2008: 266). Indicadores cronológicos similares se confirman en documentos análogos de España. Así, Calderón documenta usos tempranos del pronombre de respeto en pleitos de la Real Chancillería de Granada, fechados entre 1663 y 1665 (Calderón, 2015: 67, 181) ${ }^{8}$.

${ }^{6}$ En el tratado de Maunory (págs. 79-80) esta variante en $v$ - aparece como Vouste. Sáez Rivera indica que "la grafía ou quizá dé cuenta de $/ u /$, al tratarse de un texto en francés" (Sáez Rivera, 2006: 2907, nota 24).

${ }^{7}$ La primera documentación colonial de usted se atestigua en la correspondencia amorosa del reo Luis de Vargas con Francisca del Castillo. Estas cartas secretas, incautadas en el proceso judicial, constituyen un verdadero hallazgo documental, porque, excepcionalmente, reflejan el alejamiento del canon retórico abreviado (vmrd., etc.), implantado férreamente por los escribanos de la época. En el español peninsular, los primeros usos epistolares de usted que se conocen datan de 1755 , pero proceden de la correspondencia oficial y no tienen el carácter secreto de dichas cartas amorosas (García-Godoy, 2012: 139).

${ }^{8}$ Los ejemplos aducidos por Calderón constituyen las primeras documentaciones del plural ustedes (1663) y del singular usted (1665) en el corpus CORDEREGRA. De este corpus procede también el uso de 1653, aducido por García-Godoy (2015: 679): “¿ué me quiere ute onbre que no me dexa?". Dicho uso se documenta en un pleito malagueño, seleccionado y transcrito por la Dra. Paula Martos García, como se indica en García-Godoy (2015: 690) 
Si observamos la cronología propuesta por De Jonge y Nieuwenhuijsen (2009: 1646) para las variantes literarias más tardías (figura 2) y la comparamos con los indicadores cronológicos de la documentación histórica, podemos concluir, al menos, que existen dos visiones diacrónicas muy diferentes sobre la última fase del proceso de univerbación en los estudios previos: la sustitución vusted > usted parece un cambio culminado en la lengua teatral en el siglo XVII, mientras que en otras tipologías textuales ese cambio se prolonga una centuria más ${ }^{9}$.

Figura 2. Desarrollo de la forma vuestra merced $a$ usted con formas intermedias, observado en el CORDE (grupo-st-) (apud De Jonge y Nieuwenhuijsen, 2009: 1646, cuadro 11)

\begin{tabular}{|l|c|l|}
\hline \multicolumn{1}{|c|}{ Forma observada } & Frecuencia & Fecha \\
\hline vuestra(s) merçed(es) & 269 & $1180-1600>>$ \\
vuestra(s) merced(es) & 2734 & $1264-1700>>$ \\
vuestra mercé & 15 & $1492-1621$ \\
vuested(es) & 21 & $1619-1657$ \\
vusté & 6 & $1615-1661$ \\
vusted(es) & 39 & $1617-1668$ \\
usted(es) & p.m. & $1629>>$ \\
\hline
\end{tabular}

\subsection{El polimorfismo del pronombre de respeto: variación sociolingüistica}

Las variantes polimórficas del pronombre de respeto reciben dos valoraciones sociolingüísticas diferentes en los estudios previos. El uso de cualquier forma amalgamada se tacha de vulgar en los trabajos sobre el teatro del siglo XVII. Esta marca diastrática, omnipresente en la bibliografía especializada, se establece en virtud de los tipos teatrales que emplean tanto la forma usted, como sus alomorfos. Pla Cárceles (1923a) y, siguiendo su estela, Lapesa (1970) y De Jonge y Nieuhenhuijsen (2009) defienden el

(véase el documento [Cerón]). En el proceso de revisión del corpus CORDEREGRA, se ha revelado esta otra lectura diferente: "Qué me quiere este onbre que no me dexa". Por tal motivo, se descarta este ejemplo malagueño.

9 También los usos hispanoamericanos del plural ustedes ('vosotros') constituyen un cambio del español moderno y no del periodo clásico, como se ha venido sosteniendo. Esta nueva hipótesis cronológica, fundamentada empíricamente en la lengua no literaria, es la defendida por Calderón (en prensa). 
origen plebeyo de todas las variantes pronominales en el siglo XVII. Pla Cárceles (1923a: 271) sostiene que son "matones, bravos y gentes del pueblo" quienes emplean dichas formas en la comedia clásica. Lapesa (1970/2000: 319-320) señala tipos teatrales análogos (valentones, criadas, lacayos) y subraya la ola de plebeyez que impulsó el uso de la forma usted. Más recientemente, De Jonge y Nieuwenhuijsen (2009: 1642) indican que los alomorfos pronominales "son el producto de la lengua hablada [...] por lo tanto se suelen considerar vulgarismos”. A este respecto, Navarro Tomás (1923: 311) había sugerido que el grado de vulgaridad de una variante dependería del mayor o menor desgaste fonético: así, los alomorfos más apocopados y de más tardía aparición literaria (vusted/usted) serían también los más vulgares en el siglo XVII. Por su parte, Sáez Rivera (2006: 2907) defiende que, en la frontera de los siglos XVII y XVIII, "lo que resulta condenable o chabacano es vousted o vusted, pero no usted".

Otra valoración muy distinta del pronombre se ha rastreado en la historiografía lingüística. Frente al carácter vulgar de usted y sus alomorfos en el teatro, los primeros testimonios metalingüísticos sobre las variantes pronominales destacan su carácter netamente oral. En los tratados gramaticales del español como lengua extranjera, publicados entre 1697 y 1766, explícitamente se menciona la coexistencia del doblete vuestra merced/usted, siendo el sintagma la forma recomendada para escribir y el pronombre la variante aconsejada para hablar. Esta es la pauta de uso que describen Francisco de Sobrino en 1697 (Salvador Plans, 1996: 202; Sáez Rivera, 2006: 2904), Guillaume de Maunory en 1701 (Sáez Rivera, 2006: 2905), l'Abbé de Vayrac en 1714 (Sáez Rivera, 2006: 2907) e Hipólito Giral del Pino en 1766 (Fernández Martín, 2012: 169). En estos testimonios metalingüísticos, nunca se menciona el carácter subestándar del polimorfismo pronominal y se señalan como variantes dieciochescas, igualmente connotadas, vusted y usted. Esta segunda caracterización, como veremos más adelante, se confirma en la documentación histórica aquí explorada y también en los modelos lingüísticos registrados en el diccionario académico (véase figura 7).

En definitiva, el estadio de variación del pronombre de respeto diverge sustancialmente en la lengua literaria respecto de otras tipologías textuales. La diferente trayectoria diacrónica de las variantes pronominales en distintos géneros discursivos permite rebatir la hipótesis clásica sobre la fase final del cambio vuestra merced $>$ usted, basada exclusivamente en textos teatrales del Siglo de Oro. Igualmente, permite circunscribir el carácter subestándar de dicho cambio exclusivamente a la escena clásica. Son los géneros no literarios los que están revelando la importancia del periodo moderno (siglos XVIII-XIX) en la estandarización de las formas usted/vusted. Este hecho permite postular un ritmo más lento en la difusión de este cambio gramatical (García-Godoy, 2012; Cabal Jiménez, 2013). 


\section{El CORPUS}

El presente estudio se basa en el Corpus diacrónico del español del reino de Granada (CORDEREGRA). Este incluye documentación histórica del periodo 1492-1833, lapso en el que se desarrolla la etapa cristiana del antiguo reino nazarí. Territorialmente, dicho reino comprende las actuales provincias de Almería, Granada y Málaga. El lapso 1492-1833 coincide, además, con la historia de la Real Chancillería de Granada, institución señera en la historia judicial de España, cuya jurisdicción abarcaba el territorio sur peninsular, desde el río Tajo hasta el litoral andaluz (Calderón y García-Godoy, 2009; Calderón, 2015).

El tamaño del CORDEREGRA es de, aproximadamente, medio millón de palabras y se compone de documentación archivística inédita, transcrita con criterios de paleografía estrecha y con rigor filológico ${ }^{10}$. Las dos grandes tipologías textuales de este corpus son los inventarios de bienes (protocolos notariales) y las declaraciones de testigo (autos, probanza, sumaria información). Aunque minoritariamente, el corpus también incluye muestras del género epistolar, que, en ocasiones, aparecen intercaladas en los pleitos.

Como ya se ha indicado, para el presente estudio se explorarán solo aquellos documentos del CORDEREGRA, fechados entre 1600 y 1800, ciclo clave para analizar el polimorfismo del pronombre de respeto.

\section{EVIDENCIAS DEL PRONOMBRE DE RESPETO EN EL CORPUS}

Los investigadores del cambio vuestra merced > usted señalan las dificultades reconstructivas de la fase de univerbación en la lengua no literaria del siglo XVII, en la que apenas existen evidencias de las formas pronominales. En su estudio, De Jonge y Nieuwenhuijsen (2009) incluyen tan solo dos ejemplos no literarios de usted, hallados en un juicio mexicano de 1694. La nueva base empírica aquí explorada nos proporciona ciento cinco ocurrencias del pronombre de respeto, fechadas en el lapso 1662-1798. En

${ }^{10} \mathrm{El}$ corpus está disponible en línea en <http://www.corderegra.es > y sus 500.000 palabras presentan esta distribución cronológica: siglo XVI: 100.000 palabras; siglo XVII: 127.000 palabras; siglo XVIII: 255.000 palabras y siglo XIX (hasta 1833): 15.000 palabras (Calderón, 2015: 11). La versión actual del CORDEREGRA contiene la edición paleográfica y su primera revisión filológica. Los documentos están siendo objeto de una segunda revisión, motivo por el cual portan hoy la marca de agua "borrador". Aproximadamente al 5\% de los documentos del CORDEREGRA se les ha aplicado los criterios de edición de la red científica CHARTA, dirigida por Pedro Sánchez-Prieto. Tales documentos del CORDEREGRA se han incorporado al corpus CHARTA. En este trabajo, para facilitar la lectura de las citas del CORDEREGRA, se han eliminado algunos diacríticos de la paleografía estrecha y se han incluido los actuales signos de puntuación. 
FIGURA 3. Formas del pronombre de respeto en el corpus CORDEREGRA

(1600-1800)

\begin{tabular}{|c|c|c|c|c|c|c|c|c|c|c|}
\hline FORMA & $\begin{array}{l}1600- \\
1625\end{array}$ & $\begin{array}{l}1625- \\
1650\end{array}$ & $\begin{array}{l}1650- \\
1675\end{array}$ & $\begin{array}{l}1675- \\
1700\end{array}$ & $\begin{array}{l}1700- \\
1725\end{array}$ & $\begin{array}{l}1725- \\
1750\end{array}$ & $\begin{array}{l}1750- \\
1775\end{array}$ & $\begin{array}{l}1775- \\
1800\end{array}$ & & TOTAL \\
\hline $\begin{array}{l}\text { osted } \\
\text { osté } \\
\text { ostedes }\end{array}$ & & & $2 / 38$ & $\begin{array}{l}4 / 9 \\
2 / 9\end{array}$ & $\begin{array}{l}5 / 20 \\
1 / 20\end{array}$ & $\begin{array}{l}1 / 10 \\
2 / 10\end{array}$ & $2 / 5$ & & $\begin{array}{r}1 / 105 \\
10 / 105 \\
5 / 105\end{array}$ & $\mathbf{1 5 , 2 5 \%}(16 / 105)$ \\
\hline $\begin{array}{l}\text { usted } \\
\text { usté } \\
\text { vsted } \\
\text { ustedes } \\
\text { vstedes }\end{array}$ & & & $\begin{array}{l}15 / 38 \\
21 / 38\end{array}$ & $3 / 9$ & $\begin{array}{l}1 / 20 \\
3 / 20 \\
3 / 20\end{array}$ & $\begin{array}{l}6 / 10 \\
1 / 10\end{array}$ & $\begin{array}{l}2 / 5 \\
1 / 5\end{array}$ & $\begin{array}{l}7 / 23 \\
2 / 23\end{array}$ & $\begin{array}{r}27 / 105 \\
1 / 105 \\
12 / 105 \\
25 / 105 \\
1 / 105\end{array}$ & $62,8 \%(66 / 105)$ \\
\hline $\begin{array}{l}\text { vusted } \\
\text { busted }\end{array}$ & & & & & $\begin{array}{l}3 / 20 \\
2 / 20\end{array}$ & & & & $\begin{array}{l}3 / 105 \\
2 / 105\end{array}$ & $4,7 \%(5 / 105)$ \\
\hline V. & & & & & $1 / 20$ & & & $4 / 23$ & $5 / 105$ & $4,7 \%(5 / 105)$ \\
\hline Vd. & & & & & & & & $8 / 23$ & $8 / 105$ & $\mathbf{7 , 6 \%}(8 / 105)$ \\
\hline
\end{tabular}

la figura 3, se contabilizan todas las evidencias pronominales del corpus ${ }^{11}$, tanto las formas de singular (74), como las del plural (31). En este apartado, nos centraremos principalmente en las primeras, con el fin de responder a estas dos preguntas: ¿qué tipología textual favorece la presencia de usted y sus variantes en los siglos XVII y XVIII? ¿Cuántas ocurrencias del pronombre se manifiestan en discurso directo?

En lo atinente a la clase textual (véase figura 4), los ejemplos del pronombre en el corpus se concentran, mayoritariamente, en las declaraciones de testigo. Limitándonos a las formas de singular, observamos que 60 de las 71 ocurrencias se atestiguan en dicha tipología textual. Esta tendencia se constata en las dos centurias objeto de estudio: los ejemplos del

11 De las 105 ocurrencias del pronombre, 93 se documentan en escritura plena y 13 exhiben la innovadora abreviatura $V(d)$. Hemos contabilizado estos trece ejemplos como evidencias inequívocas del pronombre, tal y como se refleja en la figura 3. Cabe destacar que en el CORDEREGRA se revela un perfil escriturario propio de las formas pronominales, divergente del canon de escritura abreviada del sintagma. La escritura plena del pronombre de respeto, durante su primer siglo de vida, es una tendencia claramente mayoritaria en el corpus. También resulta significativo el hecho de que, en el género epistolar, todos los usos pronominales del CORDEREGRA, fechados entre 1795 y 1798, se documenten con la innovadora abreviatura $V(d)$. Para la diacronía de esta abreviatura, véase García-Godoy (2015: 670-671 y 683). 
pronombre documentados en los pleitos suponen el $100 \%$ en el siglo XVII y el 77,5\% en el siglo XVIII. En menor medida, usted aflora también en el género epistolar del corpus desde 1795. En efecto, 11 de los 71 ejemplos del pronombre de respeto singular se documentan en la correspondencia. Llama la atención el hecho de que los primeros usos epistolares de usted daten de 1795, cuando dicha forma cuenta con una trayectoria centenaria en otros géneros textuales del corpus.

FIGURA 4. Frecuencias de uso del pronombre de respeto singular en las clases documentales del CORDEREGRA

\begin{tabular}{|c|c|c|c|}
\hline Cronología & \% Protocolos & \% Pleitos & \% Cartas \\
\hline $1650-1700$ & - & $100 \%(22 / 22)$ & - \\
$1700-1750$ & - & $100 \%(18 / 18)$ & - \\
$1750-1800$ & - & $50 \%(14 / 28)$ & $50 \%(14 / 28)$ \\
\hline
\end{tabular}

Respecto del tipo de discurso (véase figura 5), merece destacarse que el $89,5 \%$ de los ejemplos pronominales del corpus se documentan en discurso directo. Contabilizadas tanto las formas de singular, como las de plural, resulta muy significativo que, desde 1665 hasta 1750 , todos los usos pronominales se atestigüen en fragmentos de discurso directo. Esta tendencia se prolonga en el CORDEREGRA hasta 1795, fecha en la que el pronombre de respeto comienza a documentarse en textos epistolares sin discurso directo.

Figura 5. Pronombre de respeto y discurso directo en el CORDEREGRA:

Frecuencia de la forma singular en discurso directo (1650-1800)

\begin{tabular}{|l|c|c|c|}
\hline Tipo DISCURSO & $1650 / 1700$ & $1700 / 1750$ & $1750 / 1800$ \\
\hline DisCURSO DIRECTO & $100 \%(47 / 47)$ & $100 \%(23 / 23)$ & $57,1 \%(16 / 28)$ \\
Otros & 0 & 0 & $42,9 \%(12 / 28)$ \\
\hline
\end{tabular}

5. VUSTED, USTED, OSTED: VARIACIÓN DIAFÁSICA Y DIATÓPICA DEL PRONOMBRE DE RESPETO EN LA LENGUA NO LITERARIA

Como ya se ha mencionado, en los estudios previos, se ofrecen noticias diversas sobre la estratificación sociolingüística del pronombre y sus 
alomorfos, dependiendo del tipo de fuente explorada y de la época. Básicamente, existen dos caracterizaciones diferentes: uso vulgar en el género teatral del siglo XVII y uso oral en la historiografía lingüística del siglo XVIII.

En este apartado, nos proponemos explorar qué tipo de estratificación revela el empleo del pronombre en nuestro corpus. Dado que el CORDEREGRA evidencia, por primera vez, la vitalidad dieciochesca de los alomorfos vusted (2), usted (3), osted (4) en la lengua no literaria, exploraremos, especialmente, las marcas del uso de estas variantes en el siglo XVIII.

(2) Declaración de Antonio Palencia, vecino de Motril, Granada [Granada 1715]. [...] bino el dicho don Miguel Ximenes [y] dijo al pressente escriuano: "compadre, deme vusted por testimonio de cómo el señor alcalde mayor saca el pescado de donde yo lo estoy repartiendo, que yo beré lo que he de aser". Y dicho señor alcalde maior dijo: "dele busted uno o treinta testimonios que lo que yo he mandado se ha de aser" y dicho don Miguel dijo: "yo tengo la jurisdiccion económica y no busted", repitiendo muchas veses con palabras descompuestas. [CORDEREGRA].

(3) Declaración de Luis de Herrera Murillo, vecino de Vélez Málaga [Vélez Málaga 1722]. [...] y el dicho $\mathrm{D}^{\mathrm{n}}$ Francisco llegó a el rreferido $\mathrm{D}^{\mathrm{n}}$ Alonso y le dixo: "ya esto se acabado, detenga usté a sus hijos, que mi hermano ya está detenido". [CORDEREGRA].

(4) Declaración de Juan Ramón Pasadas (labrador), vecino de Montefrío (Granada) [Montefrío 1753]. [...] y el que declara le respondió: "no ue osté que esta es mi calle, no iré yo donde me diere gana" a cuia respuesta el dicho Dionissio arrancó de una espada. [CORDEREGRA].

Como quiera que en el setecientos, con la creación de la RAE, se establece un canon idiomático oficial, primeramente indagaremos en el NTLLE el registro de ese trío de alomorfos pronominales, tanto en la lexicografía académica, como en la extraacadémica. En la figura 6 se demuestra cómo la RAE, en su diccionario, oficializa cierta inestabilidad formal del pronombre en etapa postclásica. Del trío de variantes pronominales atestiguadas en el corpus oste(d) es la única que nunca estuvo registrada en el DRAE. Por el contrario, las formas vusted/usted tienen carta de naturaleza académica en toda la historia del diccionario oficial de la lengua española. Solo a partir de 1803, la Academia caracteriza vusted como forma anticuada, marca que mantendrá hasta finales del siglo xx. Pero a lo largo del siglo XVIII, tanto el diccionario académico, como el de Terreros (1793), registran usted y vusted como formas equivalentes y no les otorgan ninguna marca de uso (véanse figuras 6 y 7 ).

Así pues, los principales hitos de estandarización lingüística en el español dieciochesco confirman que el pronombre de respeto tuvo dos 
FiguRa 6. Variantes pronominales y prescriptivismo lingüístico: vusted, usted, osted en el diccionario académico (1739-1992)

\begin{tabular}{|c|c|c|c|}
\hline VARIANTE & AUT. (1739) & DRAE (1780-1791) & DRAE (1803-1992) \\
\hline vusted & estándar & estándar & anticuado (ant.) \\
\hline usted & estándar & estándar & anticuado (ant.) \\
\hline osted & $\times$ & $\times$ & $\times$ \\
\hline
\end{tabular}

variantes formales (vusted/usted) que gozaron de idéntica estimación social. Por consiguiente, estos patrones del uso pronominal, censurados por la Academia, colisionan con la visión diastrática del cambio vusted > usted, en el teatro.

Veamos ahora cuál es la caracterización del uso no literario de vusted/ usted/osted, según los ejemplos del CORDEREGRA. Para ello, volveremos a revisar el estatus discursivo de estas tres formas en las tipologías textuales del corpus. Como se demuestra en la figura 5, los usos pronominales presentan una fuerte dependencia del discurso directo. No en vano, en la parte declaratoria de los autos, género oralizante por excelencia, se concentra la totalidad de ejemplos del pronombre entre 1650-1750, según se ilustra en la figura 4. Declarantes de todo el espectro social, incluidos los cargos concejiles, emplean vusted/usted/osted cuando, en la vista oral, reproducen literalmente las palabras propias o ajenas (García-Godoy, 2015: 683-685). Por el contrario, los tipos discursivos del corpus que se alejan de la oralidad y se aproximan a la escrituralidad (las cartas oficiales, los protocolos notariales) eluden cualquiera de las tres formas pronominales hasta 1795. Atendiendo a estas restricciones discursivas, podríamos sostener que vusted/usted/osted comparten, en el CORDEREGRA, su vínculo con la lengua hablada. El carácter coloquial es inherente a todos los usos pronominales del corpus, si exceptuamos algunas ocurrencias minoritarias del género epistolar. Relacionando esta nueva caracterización del pronombre con el mencionado dictamen académico, podríamos sostener que vusted y usted son formas estándares de la lengua hablada dieciochesca.

Veamos ahora la enigmática forma oste $(d)$, de gran relevancia en el corpus CORDEREGRA. Este alomorfo pronominal falta en los inventarios de variantes que han realizado los estudiosos del cambio vuestra merced $>$ usted. Asimismo, la lexicografía académica no registra oste $(d)$, ni siquiera como alomorfo subestándar. Por el contrario, en la contienda de variantes del corpus, la forma oste (d) se erige en el rival directo de usted, tanto por el número de casos (16/105), como por su longevidad casi centenaria (1662- 
1753). Si en este lapso contabilizamos las formas en os-, tanto del singular, como del plural, estas representan el 22\% de las variantes pronominales en el corpus. Resulta llamativo que las formas osted(es), opacadas por el teatro aurisecular (según los estudios previos), se atestigüen tempranamente en los pleitos criminales no solo de España, sino también de América. En el CORDEREGRA, la historia de las formas oste(d)/oste(de)s se inicia en 1662 y abarca noventa y un años, mientras que, en la documentación colonial, la variante oste(d) se atestigua en el lapso 1662-1672 (Gutiérrez Maté, 2012: 1898-1899; Gutiérrez Maté, 2015: 191). En el español contemporáneo, la geografía lingüística confirma la pervivencia dialectal de ostedes en el área central de Andalucía (ALEA, mapa 1822: pronombre personal 2a persona). La presencia de la forma en os- se circunscribe, en el siglo xx, a la zona occidental de Córdoba y algunos enclaves fronterizos con la provincia de Málaga, que constituía el occidente del antiguo Reino de Granada.

Con gran agudeza, Gutiérrez Maté (2012: 1898-1899), cuando aduce testimonios coloniales de osted en un pleito militar, subraya que el declarante tiene origen andaluz ${ }^{12}$. Por consiguiente, cabe destacar el valor añadido de los géneros dialógicos no literarios para reconstruir no solo la fase oral del cambio vuestra merced > usted, sino también la desconocida historia del polimorfismo pronominal en perspectiva diatópica: osted(es) podría ser una forma estrechamente vinculada con la historia del español meridional.

A modo de recapitulación, en la figura 7 se incluyen las distintas caracterizaciones de las formas vusted/usted, aducidas por los investigadores. Recuérdese que vusted/usted son las dos únicas variantes pronominales atestiguadas en los tres tipos documentales mencionados en este trabajo: el teatro, la historiografía lingüística y la documentación histórica del corpus CORDEREGRA. En dicha figura 7 podemos observar que existe una gran divergencia entre los parámetros de estratificación que se esgrimen en el uso teatral, respecto del resto de fuentes. Vusted/usted se conceptúan vulgarismos en el género dramático, pero en la lengua no literaria de la época esas dos formas funcionan como meros coloquialismos, sin carácter despectivo alguno. El estatus coloquial de vusted/usted se hace extensivo también al alomorfo osted, como se indica en la figura 7.

${ }^{12}$ Se trata de la declaración de Francisco de Rojas (cabo de infantería y vecino de Cádiz), en los autos contra el capitán de navío Santo Cristo de Lezo (Cartagena de Indias, 1672): "mire osted que la Capp<itana> a disparado dos piezas", "mireme osted A la tierra Y dexe osted la capp<itana $>$ que antes que Ella llegue Se an de hauer hecho dos barcadas de agua" (Gutiérrez Maté, 2012: 1898-1899). El mismo autor ofrece la más temprana documentación colonial de la forma osté, en la declaración de un soldado dominicano en 1662: "váyase osté hacia el matadero, que allá están todos juntos" (El fiscal con Salvador Márquez y Pedro Velázquez, soldados del presidio de Santo Domingo, sobre la participación de estos en un tumulto), apud Gutiérrez Maté (2015: 191). 
FIGURA 7. Variantes morfofonéticas del pronombre de respeto y tipología textual (siglos XVII-XVIII): cronología [ fecha de los testimonios] / patrones de uso / (marca)

\begin{tabular}{|c|c|c|c|}
\hline GÉNERO TEXTUAL & VUSTED & USTED & OSTED \\
\hline Teatro & $\begin{array}{l}\text { [Fecha: 1615-1668] } \\
\text { usado por matones, bravos } \\
\text { y gentes del pueblo } \\
\text { (Pla Cárceles, 1923a: } \\
\text { 271) } \\
\text { usado por valentones, } \\
\text { criadas, lacayos } \\
\text { Lapesa (1970/2000: } \\
\text { 319-320) } \\
\text { (vulgar) }\end{array}$ & $\begin{array}{l}\text { [Fecha: } 1620 / 1629>>\text { ] } \\
\text { usado por matones, bravos } \\
\text { y gentes del pueblo } \\
\text { (Pla Cárceles, 1923a: } \\
\text { 271) } \\
\text { usado por valentones, } \\
\text { criadas, lacayos } \\
\text { Lapesa (1970/2000: } \\
\text { 319-320) } \\
\text { (vulgar) }\end{array}$ & \\
\hline $\begin{array}{l}\text { Documentación } \\
\text { histórica }\end{array}$ & $\begin{array}{l}\text { [Fecha: 1714-1775] } \\
\text { uso restringido al discurso } \\
\text { directo } \\
\text { (coloquial) }\end{array}$ & $\begin{array}{l}\text { [Fecha: } 1661-1795] \\
\text { uso restringido al discurso } \\
\text { directo } \\
\text { (coloquial) }\end{array}$ & $\begin{array}{l}\text { [Fecha: 1662-1753] } \\
\text { usado en discurso } \\
\text { dir. (Andalucía) } \\
\quad \text { (coloq. + reg.) }\end{array}$ \\
\hline Gramáticas ELE & $\begin{array}{l}\text { Fecha: 1623-1701 } \\
\text { se usa para hablar } \\
\text { (coloquial) }\end{array}$ & $\begin{array}{l}\text { Fecha: 1697-1766 } \\
\text { se usa para hablar } \\
\text { (coloquial) }\end{array}$ & \\
\hline $\begin{array}{l}\text { Lexicografía } \\
\text { académica } \\
(1739-1791)\end{array}$ & $\begin{array}{l}\text { Fecha: 1739-1791 } \\
\text { (estándar) }\end{array}$ & $\begin{array}{l}\text { Fecha: } 1739 \gg> \\
\text { (estándar) }\end{array}$ & \\
\hline $\begin{array}{l}\text { Lexicografía } \\
\text { extraacad. } \\
\text { (Terreros, 1793) }\end{array}$ & (estándar) & (estándar) & \\
\hline
\end{tabular}

De acuerdo con los modelos idiomáticos descritos en la historiografía lingüística, en los usos dieciochescos del corpus, vusted, usted, osted son formas aptas para hablar, pero no tanto para escribir. El uso de este trío de alomorfos en el CORDEREGRA tiene la misma motivación diafásica, aunque entre ellos pueda advertirse diferente grado de estandarización: así, mientras que las formas vusted/usted han sido seleccionadas, indistintamente, por 
la lengua estándar dieciochesca, con el visto bueno de la RAE, osted pudo ser una forma restringida al habla dialectal de Andalucía, que no gozó del parabién académico.

\section{Conclusiones}

La documentación no literaria sustenta una nueva historia del pronombre de respeto. Asimismo, dicha documentación pone de relieve las divergencias históricas de usted dentro y fuera de la escena clásica, principalmente en tres aspectos: número de variantes univerbales del pronombre, diacronía de los distintos alomorfos, estratificación del uso.

En lo atinente al polimorfismo pronominal, se establece un inventario de diecisiete variantes morfofonéticas en el género dramático, frente a solo tres en la documentación histórica del CORDEREGRA: vusted/usted/osted. De esta última variante solo existen evidencias en los documentos históricos del ámbito meridional. Por el contrario, vusted/usted son formas atestiguadas en cualquier tipo de fuente. Considerando este hecho, la hipótesis tradicional sobre el profuso polimorfismo de usted parece insostenible en la lengua no literaria. El inventario oficial de alomorfos pronominales, muy mayoritariamente, existió solo en el uso teatral. La aparición literaria de formas como vuesansçed, vuesansted, uçed, etc., pudo obedecer a condiciones retóricas del género dramático, alejadas del uso real. De las diecisiete variantes incluidas en la genealogía oficial del pronombre de respeto, muy probablemente, quince han tenido solo vida literaria.

Cronológicamente, también existen divergencias sobre la longevidad del polimorfismo pronominal dentro y fuera de la escena clásica. La defunción literaria de todos los alomorfos se ha fechado en los últimos años del siglo XVII, mientras que en los géneros no literarios vusted/usted/osted coexisten en el siglo XVIII. En esta centuria, la RAE oficializa la variación de vusted/usted, como únicas variantes pronominales, igualmente connotadas en el uso dieciochesco. La historia del pronombre de respeto no finaliza en la época clásica, sino que se prolonga en la Edad Moderna de la lengua española.

Por último, el tipo textual y su grado de dialogismo permiten reconstruir diferentes marcas de uso del pronombre de respeto. En la base empírica no literaria, la interfaz oral/escrito vertebra el cambio vuestra merced $>$ usted. Las variantes pronominales son formas vitandas en el canon de lengua escrita, toda vez que la mayoría de géneros textuales favorece la conservación del sintagma primigenio vuestra merced e inhibe sus evoluciones fonéticas orales, que se estaban desarrollando en la lengua hablada. De ahí que las evidencias documentales del pronombre se localicen solo en 
los géneros de impronta oral: diálogos teatrales en la literatura y discurso directo en la documentación histórica. Así, en el corpus CORDEREGRA, todos los usos pronominales se atestiguan en discurso directo hasta 1795, fecha en que se datan los primeros usos de usted en el género epistolar. Según estos indicios, el pronombre se emancipa de las tipologías textuales oralizantes e incursiona, definitivamente, en la lengua escrita general a finales del siglo XVIII. Hasta entonces, el hábitat natural del pronombre se limitaba a los diálogos teatrales de las clases bajas (uso vulgar) y al discurso directo en los documentos históricos (uso coloquial). Por tal motivo, la aparición del pronombre en la lengua literaria se viene conceptuando un fenómeno subestándar y estigmatizado, mientras que en la lengua no literaria ese mismo fenómeno tiene carácter estándar y oral. Centrándonos en el último eslabón evolutivo vusted > usted, ni la documentación histórica de los siglos XVII-XVIII, ni los modelos lingüísticos prescriptos por la RAE, ni los usos idiomáticos recomendados en las gramáticas de español para extranjeros, permiten confirmar el carácter subestándar advertido en los usos teatrales de ambas formas pronominales. En efecto, son factores diafásicos y no diastráticos los que determinan los usos del pronombre de respeto durante su primer siglo de vida. Por consiguiente, no existen pruebas empíricas para seguir manteniendo el origen vulgar y plebeyo del pronombre de respeto, cuyo proceso de estandarización se prolongó durante todo el siglo XVIII con dos alomorfos (vusted/usted) que tuvieron vitola académica. 


\section{BIBLIOGRAFIA}

Alea (1991 [1961]): Alvar, M. [con la colaboración de A. Llorente y G. Salvador], Atlas Lingüistico y Etnográfico de Andalucía, Madrid, Gredos.

Alvar, M. y Pottier, B. (1983): Morfología histórica del español, Madrid, Gredos.

BARRAZA CARbajal, G. (2014): "Oraciones subordinadas sustantivas de objeto directo”, en Concepción Company (dir.), Sintaxis histórica de la lengua española. Tercera parte: Preposiciones, adverbios y conjunciones. Relaciones interoacionales, vol. III, México, UNAM/FCE, págs. 2973-3106.

Cabal JimÉnez, M. (2013): From deference to face: the evolution of usted in Costa Rican Spanish, University of Illinois at Urbana Champaign.

Calderón Campos, M. y García-Godoy, M. T. (2009): "El corpus diacrónico del español del Reino de Granada (CORDEREGRA)", en A. Enrique-Arias (ed.), Diacronía de las lenguas iberorrománicas. Nuevas aportaciones desde la lingüistica de corpus, Madrid/Frankfurt, Iberoamericana/Vervuert, págs. 229-251.

- (2015): El español del reino de Granada en sus documentos (1492-1833). Oralidady escritura, Berna, Peter Lang.

- (en prensa): "Pérdida del pronombre vosotros y su paradigma", en J. P. Sánchez Méndez y E. Rojas Mayer (eds.), Morfosintaxis histórica de las hablas americanas. El pronombre, Tirant lo Blanch, Serie Diachronica Hispanica, Universidad de Neuchâtel/Tirant lo Blanch.

Cano Aguilar, R. (2000): "Oración compleja y estructura del discurso: nuevos desarrollos en sintaxis histórica del español”, Revista de Investigación Lingüística 2/3, págs. 95-122.

[CHARTA] P. Sánchez-Prieto Borja (dir.): Corpus Hispánico y Americano en la Red: Textos Antiguos. <www.charta.es>.

Company, C. (2008): "Gramaticalización, género discursivo y otras variables en la difusión del cambio sintáctico", en J. Kabatek (ed.), Sintaxis histórica del español y cambio lingüistico: nuevas perspectivas desde las Tradiciones Discursivas, Madrid/Frankfurt, Vervuert/Iberoamericana, págs. 17-52.

[CORDE]: Real Academia Española, Banco de datos corde [en línea]. Corpus Diacrónico del Español <www.rae.es> [septiembre de 2015].

[CORDEREGRA]: M. Calderón Campos y M. T. García-Godoy (dirs.): Corpus diacrónico del español del reino de Granada (1492-1833), (edición borrador 2015), $<$ www.corderegra.es $>$ [septiembre de 2015].

DE Jonge, B. (2005): "El desarrollo de las variantes de vuestra merced a usted", en Actas del II Congreso de la Región Noroeste de Europa de la Asociación de Lingüística y Filología de América Latina (ALFAL), Estudios de Lingüistica del Español (ELiEs), 22, $<$ http://elies.rediris.es/elies22>.

- y Nieuwenhuijsen, D. (2009): "Formación del paradigma pronominal de las formas de tratamiento", en C. Company Company (dir.), Sintaxis histórica de la lengua española. Segunda parte: la frase nominal, México, UNAM/FCE, vol. II, págs. 1595-1671. 
De Stefano, L. y Tejera, Ma J. (eds.) (2006): Documentos para la historia del español de Venezuela, Universidad Central de Venezuela/Facultad de Humanidades y Educación/Instituto Andrés Bello [CD].

Eberenz, R. (2000): El español en el otoño de la Edad Media, Madrid, Gredos.

FERnández Martín, E. (2012): "Vosotros/ustedes. Estudios del tratamiento plural en el español dieciochesco”, en M T. García-Godoy (ed.), El español del siglo XVIII. Cambios diacrónicos en el primer español moderno, Berna, Peter Lang, págs. 153-194.

García-Godoy, M ${ }^{\mathbf{a}}$ T. (2012): "El tratamiento de merced en el español del siglo XVIII", en Ma T. García-Godoy (ed.), El español del siglo XVIII. Cambios diacrónicos en el primer español moderno, Berna, Peter Lang, págs. 111-152.

- (2015): "El cambio vuestra merced > usted desde la documentación archivística", en J. P. Sánchez Méndez, M. de la Torre y V. Codita (eds.), Temas, problemas y métodos para la edición y el estudio de documentos hispánicos antiguos, Valencia, Tirant Humanidades, Colección Diachronica Hispanica, págs. 661-694.

GutiÉRREZ Maté, M. (2012): "El pronombre usted en el español de Cartagena de Indias del siglo XVIII y su 'divergencia' de vuestra merced", en E. Montero Cartelle (ed.), Actas del VIII Congreso Internacional de Historia de la Lengua Española (Santiago de Compostela, 14-18 de septiembre de 2009), Santiago de Compostela, Meubook, págs. 1889-2004.

- (2015): "Las 'representaciones difusas' de los documentos dominicanos y su estudio lingüístico-variacional”, en J. P. Sánchez Méndez, M. de la Torre y V. Codita (eds.), Temas, problemas y métodos para la edición y el estudio de documentos hispánicos antiguos, Valencia, Tirant Humanidades, Colección Diachronica Hispanica, págs. 177-196.

KАВАТЕК, J. (2005): “Tradiciones discursivas y cambio lingüístico”, Lexis 29/2, págs. 151-178.

Koch, P. (2008): "Tradiciones discursivas y cambio lingüístico: el ejemplo del tratamiento vuestra merced en español", en J. Kabatek (ed.), Sintaxis histórica del español y cambio lingüistico: nuevas perspectivas desde las Tradiciones Discursivas, Madrid/Frankfurt, Vervuert/Iberoamericana, págs. 53-88.

LAPESA, R. (2000 [1970]): "Personas gramaticales y tratamientos en español", en Homenaje a Menéndez Pidal, Madrid, Universidad de Madrid, vol. IV, 121-167; 2) (2000) en Estudios de morfosintaxis histórica, Madrid, Gredos, vol. II, págs. 311-345.

LEÓN, A. E. (1998): "Bosquejo diacrónico de vusted > usted", en C. García Turza et al. (eds.), Actas del IV Congreso Internacional de Historia de la Lengua Española, La Rioja, Universidad de la Rioja/Gredos, págs. 565-572.

Lleal Galcerán, C. (2013): "Rigor metodológico e investigación filológica", Scriptum digital, 2, págs. 107-121.

Ly, N. (2001): "La interlocución en el teatro del Siglo de Oro: una poética de la interferencia”, Criticón, 81/82, págs. 11-28.

Melis, Ch. y Rivero Franyutti, A. [con la colaboración de Beatriz Arias Álvarez] (2008): Documentos Lingüisticos de la Nueva España. Golfo de México, UNAM, México.

NAVArro Tomás, T. (1923): “'Vuesasted', ‘usted”, RFE, X, págs. 310-311. 
[NTLLE] Real Academia Española, diccionarios (en línea): Nuevo Tesoro Lexicográfico de la Lengua Española. <www.rae.es>

OESTERREICHER, W. (2011 [1990]): “Textos entre inmediatez y distancia comunicativas. El problema de lo oral en lo escrito. El problema de lo hablado escrito en el Siglo de Oro", en R. Cano (ed.), Historia de la lengua española, Barcelona, Ariel, págs. 729-769.

Pla CÁrceles, J. (1923a): "La evolución del tratamiento "vuestra merced'”, RFE, X, págs. 245-280.

- (1923b): "Vuestra merced > usted", RFE, 10/2, págs. 402-403.

[RAE-ASALE] Real Academia Española/Asociación de Academias de la Lengua Española (2009): Nueva Gramática de la Lengua Española, Madrid, Gredos.

SÁEz Rivera, D. M. (2006): "Vuestra merced > usted: nuevos datos y perspectivas", en J. J. Bustos Tovar y J. L. Girón Alconchel (eds.), Actas del VI Congreso Internacional de Historia de la Lengua Española (Madrid, 29 de septiembre-3 de octubre de 2003), Madrid, Arco/Libros, vol. III, págs. 2899-2912. 